\title{
Emma Sköldberg*
}

\section{När faktorer lyser med sin frånvaro: om några typer av betydelsevariation hos svenska} idiom

\begin{abstract}
In this paper, I explore certain types of semantic variation that recur in 36 Swedish idioms when used in contemporary newspaper material (slightly more than 33.7 million running words). The semantic analysis of the idioms is influenced by studies of lexemes. The idioms are described according to the principle of factor analysis, meaning that I have attempted to differentiate semantic factors that can be considered building blocks in the internal semantic structure constituting the conventionalized meaning of the idioms. Definitions of the expressions were then based on the semantic factors. One type of variation entails the manifestation of a specific semantic factor in certain cases when the idiom is used. Other times, the relevant factor is absent. In a different type of variation, one particular semantic factor is replaced by another. The study reported here should be useful in a variety of ways, including as a basis for comparison between how semantic variation appears in different types of fixed phrases and lexemes.
\end{abstract}

\section{Introduktion}

Uttrycksmässig variation, dvs. variation av formen, hos fraseologiska enheter som t.ex. idiom har studerats i ett antal olika sammanhang och beträffande olika språk (se t.ex. Koller 1977; Barkema 1996, 1997; Corpas Pastor 1996; Moon 1998). Däremot är inte variation hos den idiomatiska betydelsen - som alltså inte kan sägas vara en direkt konsekvens av att uttryckets form modifierats - lika flitigt undersökt. Den här typen av semantisk variation uppträder exempelvis hos det svenska idiomet hänga $i$ luften. Uttryckets olika betydelsenyanser framkommer i dessa båda autentiska exempel, som är hämtade ur Språkbankens pressmaterial (kursiveringar i exemplen är mina egna):

\footnotetext{
* Fil. dr Emma Sköldberg Institutionen för svenska språket Göteborgs universitet, Box 200, SE-405 30 Göteborg Emma.Skoeldberg@svenska.gu.se
} 
(1) Men om den inledande halvtimmen var bra, blev fortsättningen desto ängsligare. Sedan Yolanda Mateos reducerat till 2-1 bara tre minuter efter Sveriges 2-0-mål tog spanjorskorna över matchen. 2-2 hängde $i$ luften nästan hela tiden i den andra halvleken [...]. (Press 98)

(2) Hur är läget så här 50 dagar före festivalstarten? - Mycket hänger $i$ luften fortfarande. En stor del av programmet och gästerna är ännu inte spikade. (Press 97)

I exempel (1) kan uttrycket sägas betyda '(tyckas) vara nära förestående' (jfr Nationalencyklopedins ordbok 1995-96 s.v. hänga). I användningar av detta slag är det - åtminstone ur någon eller någras perspektiv - något mer eller mindre negativt eller hotfullt som förefaller vara nära förestående. Det förblir dock ovisst om det negativa verkligen förverkligas. I exempel (2) kan man säga att uttrycket betyder 'vara osäkert' (se vidare i Sköldberg 2004: 78). Den omnämnda festivalens program är ännu inte helt fastlagt. I exempel av detta slag har sålunda osäkerheten, dvs. det ovissa, blivit dominerande.

I den mån betydelsevariation hos fasta fraser diskuteras är det $\mathrm{i}$ hög grad i form av svepande kommentarer om de fasta uttryckens semantiska spännvidd och eventuella kontextberoende. Några exempel på sådana generella uttalanden om fasta frasers betydelsevariation återfinns i exempelvis Lindfors Viklund (1991: 2) och Clausén (1996: 37) (se vidare i Sköldberg 2004: 75-76).

Hos bl.a. Fleischer (1997: 166-169) och Burger (1998: 72) problematiseras emellertid förekomsten av polysemi hos fasta fraser. Enligt Moon (1998: 187) har ett polysemt uttryck två eller flera icke-kompositionella betydelser utöver den bokstavliga (kompositionella) innebörden. En bidragande orsak till att polysemi hos fasta fraser inte behandlas i högre utsträckning kan vara att polysemi helt enkelt inte förekommer så ofta bland fasta fraser som bland lexem, dvs. vanliga ord (jfr bl.a. Dobrovol'skij 1992: 288; Burger 1998: 72).

I Sköldberg (2004) redogör jag för den semantiska variation som kommer till uttryck i bruket av 36 svenska idiom. Jag visar bl.a. att det råder en markant skillnad mellan olika idiom vad gäller graden av betydelsevariation. Drygt hälften av de undersökta uttrycken uppvisar en starkt begränsad semantisk variation. Bland dessa återfinns t.ex. bära frukt ('ge önskat resultat') och rinna ut i sanden ('inte leda till något'). Övriga idiom varierar desto mer. Ett av dessa idiom är kasta ljus över något med definitionen '(genom att uppmärksamma, ytterligare belysa 
e.d.) bidra med ytterligare information om något'. Ett annat idiom som också hör till denna senare kategori är sopa något under mattan med betydelsen 'dölja el. på något sätt försöka undvika el. negligera något'.

I den här artikeln vidareutvecklar och fördjupar jag några av de resonemang som förs kring semantisk variation i Sköldberg (2004). Mitt syfte är att på ett ännu tydligare sätt lyfta fram några typer av betydelsevariation som återkommer bland svenska idiom i bruk. Denna artikel kan bl.a. tjäna som utgångspunkt för en jämförelse mellan hur semantisk variation uppträder hos olika typer av fasta fraser och enkla lexem i svenskan. Den studie som presenteras här kan också utgöra grunden i en mer omfattande undersökning av hur semantisk variation uppträder hos svenska idiom respektive idiom i andra språk. Studien kan i förlängningen också vara användbar i exempelvis lexikografiska sammanhang, i synnerhet då fasta fraser skall definieras.

I det följande presenteras först det material som jag utgått ifrån i samband med undersökningen samt de teoretiska utgångspunkter som ligger till grund för den. Därefter presenteras undersökningens resultat. Artikeln avslutas med en kortfattad diskussion.

\section{Material}

Studien är baserad på hur 36 svenska idiom används i ett samtida pressmaterial, nämligen Press 95, Press 96, Press 97 och Press 98. Dessa material utgör en del av det totala textmaterial som ingår i Språkbanken vid Göteborgs universitet. (För en utförligare presentation av Språkbanken, se t.ex. nätadressen $<$ http://spraakbanken.gu.se $>$ ). Materialen Press 95-Press 98 innehåller sammanlagt närmare 33,7 miljoner löpande ord, och texterna är skrivna mellan 1995 och 1998. Undersökningen är därmed synkron. Det finns flera orsaker till att jag valt att undersöka just tidningstexter, men ett viktigt skäl är det rikliga bruket av fasta uttryck i tidningar (se bl.a. Skog-Södersved 1992; Burger 1999: 77).

De undersökta uttrycken har åtminstone tre gemensamma egenskaper. För det första kan de alla, i enlighet med följande definition, betraktas som prototypiska idiom:

Ett prototypiskt idiom är en institutionaliserad sammanställning av lexikaliska enheter och bildar som helhet en syntaktisk konstruktion, som utan att ha en huvudsakligen grammatisk eller textbindande funktion fungerar som en del av en mening eller sats, har relativt fixerad 
form samt en figurativ betydelse som inte är härledbar ur de ingående ordens betydelse. (Sköldberg 2004: 29)

Det faktum att alla uttrycken är upptagna i Målande uttryck. En liten bok med svenska idiom (1989) pekar dessutom på att de är väletablerade. För det andra består samtliga uttryck av ett verb jämte komplement. De har alltså i viss mån likartad struktur. För det tredje förekommer samtliga idiom en gång eller mer per en miljon löpord i det ovan nämnda pressmaterialet. Idiomen torde av denna orsak kunna betraktas som förhållandevis frekventa (jfr t.ex. Moon 1998: 61). Antalet förekomster av de undersökta idiomen varierar emellertid mycket. Bland de mest frekventa uttrycken finns bl.a. inte sticka under stol med något ('inte försöka dölja något') med 101 belägg. Bland idiomen med relativt få förekomster återfinns exempelvis fä blodad tand ('bli inspirerad att fortsätta med el. utvidga viss verksamhet') med 33 belägg.

\section{Teoretiska utgångspunkter}

Vid de semantiska analyserna av de aktuella uttrycken har jag influerats av den lexikala forskning som sedan några decennier har bedrivits vid Institutionen för svenska språket/Språkdata vid Göteborgs universitet. Några arbeten inom denna tradition är bl.a. Järborg $(1989,1996,2003)$ och Toporowska Gronostaj (1996). Av stor vikt i sammanhanget är projektet "Lexikalisk databas/Svensk ordbok", som genomfördes mellan 1978 och 1986. Genom projektet etablerades en databas, "Göteborgs universitets lexikaliska databas" (GLDB), som sedermera har legat till grund för en rad forskningsprojekt och enspråkiga ordböcker såsom Svensk ordbok (1986 jämte flera senare bearbetningar) och Nationalencyklopedins ordbok (1995-96).

I den teoretiska modell som ligger till grund för databasen är lexemen beskrivna enligt faktoranalysprincipen. Denna princip innebär att man försöker urskilja semantiska faktorer, vilka kan sägas vara byggstenar i den inre semantiska struktur som utgör lexemets kärnbetydelse (Järborg 1989: 13). De semantiska faktorerna ligger sedan till grund för definieringen av lexemet. Inom modellen eftersträvas en s.k. analytisk definition, vilken är formulerad så att varje faktor som urskiljs vid analysen beskrivs med ett eget ord eller en egen fras i definitionstexten (Järborg 1989: 53). I enlighet med modellen kan en kärnbetydelse modifieras till olika användningsbetydelser med hjälp av en 
uppsättning av generella lexikalisk-semantiska regler, kallade semantiska transfereringsregler. Vidare kan en lexikaliserad betydelsemodifikation av en given kärnbetydelse kallas (lexikaliserad) underbetydelse (Järborg 1989: 7-8, 1996: 3, 12). Förhållandet mellan en kärnbetydelse och en underbetydelse kan bestå i att en semantisk faktor lyfts fram ytterligare eller att en semantisk faktor tonas ned, försvagas eller faller bort (Järborg 1996: 27; Norén 1996: 23).

Sammanfattningsvis kan man alltså säga att lexemet på innehållssidan betraktas som en enhet med välbestämd kärna men med diffusa gränser (Järborg 1996: 12; Norén 1996: 23). Så till vida kan man säga att de forskare som tillämpar denna modell ansluter sig till en teori som enligt Aitchison (2003: 52) går ut på att ords betydelser är "essentially fluid". Inom projektet "Lexikalisk databas/Svensk ordbok" och den lexikala forskning som det givit upphov till, har forskarna framför allt studerat lexem. Idiom har däremot kommit i skymundan (Järborg 1989: 2, 6667). Det etablerade arbetssättet beträffande lexem har dock visat sig vara användbart även vid undersökningar av idiomatiska uttrycks betydelser (se Sköldberg 2004: 84-85, 104-173).

\section{Undersökningens resultat}

För att klarlägga de aktuella uttryckens idiomatiska betydelse har jag framför allt analyserat hur idiomen används i det angivna pressmaterialet. Men jag har också utgått från min egen språkliga intuition och diskuterat bruket av idiomen med andra infödda talare i min omgivning. Slutligen har jag, för att få uppslag och jämförelsematerial, granskat hur de aktuella idiomen definieras i Svenska Akademiens ordbok över svenska språket (1898-) och Nationalencyklopedins ordbok (1995-96).

De aktuella idiomen varierar som sagt i olika hög grad. Oavsett uttryckens variationsgrad kan man emellertid urskilja olika typer av variation. Vissa variationsmönster återkommer alltså. Nedan diskuteras först variation som består i att en specifik semantisk faktor realiseras i vissa belägg på idiomet, men inte i samtliga. Sedan redogör jag för variation som består $i$ att en semantisk faktor byts ut mot en annan faktor. Därefter tar jag upp variation som rör idiomens externa argument, dvs. variation som har med uttryckens semantiska valens att göra (jfr Toporowska Gronostaj 1996: 218; Sköldberg 2004: 83-84). 
Avslutningsvis diskuteras fall där variationen rör såväl specifika semantiska faktorer som uttryckens semantiska valens.

\subsection{Realisering/icke-realisering av semantisk faktor}

De olika semantiska faktorerna bildar alltså tillsammans idiomets grundbetydelse. Vissa av dessa faktorer kan dock betraktas som optionella och de realiseras endast i vissa belägg. Ett uttryck som har en sådan optionell semantisk faktor är dra växlar på något. Idiomets betydelse kan sägas vara 'dra slutsatser (som indikerar fortsatt positiv utveckling) av något'. (Uttryckens definitioner är, om inget annat anges, hämtade från Sköldberg 2004). Som framgår av definitionen kan de aktuella slutsatserna antyda att framtiden i något avseende är positiv. Så är också fallet i exempel (3):

(3) Lööf aktar sig dock för att dra för stora växlar på storsegern. - Vi ska passa oss för att sticka ut hakan, så här stora ytor kommer vi inte få i nästa match. (Press 97)

I (3) handlar det om vilka slutsatser man kan dra av en "storseger" i en fotbollsmatch. Laget ifråga har vunnit överlägset och det bådar gott inför framtiden. Den omtalade "Lööf" vill dock inte ta ut några segrar i förskott. Den semantiska faktorn 'som indikerar fortsatt positiv utveckling' är dock inte alltid närvarande när detta idiom används och av detta skäl står den inom parentes i definitionen. Den aktuella faktorn realiseras exempelvis inte i följande belägg:

(4) Vilka framtidsdrömmar hyser då dagens barn? Utan att dra alltför stora växlar på denna artikel, vilken bygger på intervjuer med blott sex pojkar och flickor i låg- och mellanstadieåldern, vågar man nog ändå dra slutsatsen att dessa barn är tidstypiska i den bemärkelsen att flera av dem drömmer om att som vuxna arbeta inom mediaindustrin - så t.ex. Monica, 10 år, som hoppas bli journalist för att på så vis få träffa sin idol Robyn. (Press 96)

I exempel (4) handlar det om att dra en slutsats av innehållet i en viss artikel. Denna slutsats är dock varken utpräglat positiv eller negativ utan förhållandevis neutral. Man skulle kunna säga att bortfallet av faktorn 'som indikerar fortsatt positiv utveckling' leder till en generalisering av uttryckets idiomatiska betydelse. Denna ordning, som innebär att man utgår från det belägg där den aktuella faktorn specificeras och därefter tar upp fall där faktorn inte manifesteras, är i enlighet med de seman- 
tiska analyserna av lexem i den lexikaliska databasen GLDB (se vidare Järborg 2003: 9).

Ett annat uttryck som har semantisk faktorer som endast realiseras i vissa fall är kasta in handduken. Den semantiska variationen hos uttrycket framgår av idiomets definition som är följande: '(motvilligt) bestämma sig för att (efter någon form av kamp) sluta med el. ge upp något'. I flertalet av beläggen i materialet är det fråga om en person som ägnar sig åt något eller har för avsikt att genomföra något speciellt. Ett kännetecknande drag är att det oftast handlar om medverkan i någon form av konkurrenssituation. Av olika skäl måste dock personen ifråga sluta med detta. Många gånger handlar det om att motvilligt och efter viss kamp ge upp. Personen skulle alltså gärna vilja fortsätta med den aktuella aktiviteten. Så är också fallet i exempel (5):

(5) Sveriges tvåa i grenen, Kurre Lansburgh, tvingades att kasta in handduken efter sitt första finalåk. Han vann åket, men fick en låsning $\mathrm{i}$ ryggen efter det första hoppet och kunde inte tävla vidare. (Press 98)

I just detta exempel måste en viss idrottsman ge upp i en tävling på grund av en ryggskada. Formuleringen "tvingades att kasta in handduken" förstärker också intrycket av att han gärna fullföljt tävlingen om han hade kunnat. I andra belägg är dock de semantiska faktorerna 'motvillighet' och 'efter någon form av kamp' inte lika påtagliga. Man kan då säga att personen eller personerna helt enkelt har slutat med något. Denna betydelse överväger i exempel (6):

(6) Det är förresten femtonårsjubileum för minifestivalen i Himlabacken. Där var det reggae i det fria onsdagen den 17 juni 1981 med Cab, göteborgska Watoto, Peps-gitarristen Tony Ellis Band, och engelska toppattraktionen Steel Pulse. Samma år kastade Nationalteatern in handduken efter att ha krönt karriären med två framträdanden på Roskildefestivalen. Nu festar de loss på nytt, med Jack Ripper, Speedy Gonzales, Greven, Plast och de andra. (Press 96)

I (6) omtalas att medlemmarna i en musikgrupp på eget initiativ och utan tvång valde att sluta spela tillsammans. Möjligen implicerar valet av uttryckssätt att den period som håller på att gå mot sitt slut trots allt har innehållit kampmoment. Just musikgruppen Nationalteatern utgjorde nämligen en "samlingspunkt för 1970-talets alternativkultur" (Nationalencyklopedin 1994, band 14: 45). 


\subsection{Utbyte av semantisk faktor}

En annan typ av variation kan sägas bestå i ett utbyte av en (eller flera) semantisk(a) faktor(er). I vissa fall är en semantisk faktor aktuell, i andra fall en annan. Den här typen av variation gäller bl.a. sopa något under mattan. Definition 'dölja el. på något sätt försöka undvika el. negligera något' speglar de betydelsenyanser som uttrycket har i faktiska texter. De delvis skiftande betydelserna framträder i exempel (7)-(9):

(7) Samper anklagades för att ha stoppat pengar ur partikassan i egna fickor, urkundsförfalskning, valfusk och för att ha försökt sopa hela affären under mattan. (Press 96)

(8) NEW YORK: Abortfrågan intar plötsligt återigen den politiska scenen i USA. Det republikanska partiet hade hoppas kunna sopa aborterna under mattan inför nästa presidentval men nu har den viktiga kristna högern dragit fram abortfrågan genom ett ultimatum till partiet. (Press 95)

(9) Barn på mellanstadiet behöver någonstans att träffas på eftermiddagarna när föräldrarna jobbar. Per Hedberg trodde att den nya barnomsorgslagen skulle innebära detta och att Jakob äntligen skulle få tillgång till en fritidsklubb. "En glömd grupp". Barnen mellan tio och tolv år är en glömd grupp. De ska kunna klara sig själva och barnens egna behov är lätta att sopa under mattan. (Press 95)

En genomgång av materialet visar att det är relativt skilda ting som man försöker sopa under mattan. I de allra flesta fall rör det sig dock om något som betraktas som känsligt. I exempel (7) försöker man tysta ner det faktum att pengar ur partikassan använts på ett otillbörligt sätt. Man kan säga att idiomet i det fallet betyder 'dölja något obehagligt'. I exempel (8) utpekas en känslig fråga, dvs. "aborterna". Man försöker här att undvika ett ämne som vållar problem. I vissa fall innebär dock inte sopa något under mattan på samma sätt ett aktivt ställningstagande med konkreta åtgärder som följd. I exempel (9) kan man säga att "barnens egna behov" har fått stå tillbaka. De har medvetet eller omedvetet glömts bort. Uttrycket sopa något under mattan betyder då närmast 'negligera något'.

Ett annat idiom som också uppvisar den här typen av variation är idiomet få blodad tand. Jag har valt att ge det följande definition: 'bli inspirerad att fortsätta med el. utvidga viss verksamhet'. Den semantiska variationen hos idiomet är starkt begränsad i materialet. I en klar majoritet av fallen handlar det om en person som har varit med om en positiv 
upplevelse, t.ex. en framgång av något slag. I vissa fall handlar det om en ny aktivitet. Den positiva erfarenheten leder till att personen vill prova på aktiviteten igen. I andra fall ägnar sig personen ifråga redan åt aktiviteten $\mathrm{i}$ viss mån, men tack vare den positiva upplevelsen, vill han eller hon ägna sig åt aktiviteten i högre grad än tidigare. Med andra ord vill personen utvidga denna verksamhet.

\subsection{Variation kopplad till idiomets semantiska valens}

Nästa typ av variation gäller idiomens semantiska valens. Denna typ av variation klarläggs vid en granskning av vad de externa argumenten representeras av för semantiska klasser. För att förtydliga kan jag säga att uttrycket $X$ rinner ut $i$ sanden (dvs. 'X leder inte till något') har ett argument (här angivet med $X$ ), vilket syntaktiskt fungerar som subjekt till uttrycket. En intressant fråga är vilket eller vilka typer av semantiska klasser som vanligtvis representerar detta argument. I just detta fall brukar argumentet representeras av ett abstrakt substantiv (såsom t.ex. förslaget och projektet).

Ett uttryck som är aktuellt i detta sammanhang är lysa med sin frånvaro, som har följande betydelse 'väcka uppseende genom att saknas vid en plats, en situation e.d. där personen e.d. ifråga förväntas vara närvarande' /om person, föremål, företeelse e.d./ Såsom framgår av definitionstillägget (som återges inom snedstreck) och exempel (10)-(12) nedan kan relativt skilda företeelser väcka uppseende genom att saknas.

(10) På marknaden lyste livsmedlen med sin frånvaro. Det var lättare att köpa sig ett sovjetiskt automatvapen av märket Kalasjnikov än ett kilo potatis. (Press 97)

(11) De 25 närvarande ledarna - bland andra Sveriges och Danmarks statsministrar lyste med sin frånvaro - enades om att utveckla samarbetet inom handel och investeringar. (Press 96)

(12) Göran Persson blev slagen i huvudet med sin brittiske partibroder Tony Blair, som drastiskt reformerat Labour i liberal riktning. Sådan förnyelse lyser med sin frånvaro i den svenska socialdemokratin sade folkpartiets Lars Leijonborg. (Press 97)

Uppenbarligen kan såväl konkreta ting som livsmedel, officiella personer som statsministrar och abstrakta företeelser som förnyelser lysa med sin frånvaro. Oavsett vad som saknas är frånvaron påfallande, eftersom någon form av närvaro är förväntad. I grund och botten är denna va- 
riation ganska trivial. Men med tanke på att uttryck som rinna ut i sanden, som uppvisar starkt begränsad betydelsevariation, inte ens varierar beträffande de semantiska klasser som representerar uttryckets externa argument, bör denna typ av variation ändå nämnas.

Ett annat uttryck som också uppvisar variation beträffande idiomets externa argument är bära frukt, vars betydelse är 'ge önskat resultat'. I materialet är det språkliga uttryck som fungerar som uttryckets subjekt i princip alltid abstrakt. Oftast åsyftas någon form av arbete eller satsning. Så är också fallet i exempel (13):

(13) Nya investeringar är en förutsättning för att de ekonomiska reformerna ska bära frukt och tillväxten ska kunna ta fart. (Press 97)

I några fall är det dock frön som ger önskat resultat och det kan tyckas vara förbryllande. Ett av dessa belägg återges som (14):

(14) Men att den ryska positionen i grunden verkligen förändrats radikalt visar utrikesminister Primakovs svar på presskonferensen om sin syn på det "nya Nato" som alliansen sjösatte i Berlin i juni i år. [...] Även om de frön som såtts ännu inte vuxit och burit frukt följer vi noga med. Primakovs ordval där Nato agerar såningsman har framförts förr - men med rakt motsatt negativ innebörd. (Press 96)

I (14) talas det om frön som såtts, men som ännu inte vuxit, samt om Nato som agerar "såningsman". Med andra ord kan såväl den bokstavliga betydelsen hos idiomet som andra ord i textavsnittet hänföras till den semantiska sfären 'växtlighet'. Idiomet genererar alltså koherenta metaforer i närkontexten, och det tyder på att just detta idiom kan uppfattas som en levande metafor (jfr t.ex. Svanlund 2001: 25-26).

\subsection{En kombination av flera variationstyper}

Hittills har jag diskuterat idiom vilkas variation i någon mån kan renodlas till en särskild typ. De olika variationstyperna sammanfaller dock ofta. Så är exempelvis fallet med idiomet sätta käppar $i$ hjulet för någon eller något med definitionen '(avsiktligt) vålla (oöverstigligt) hinder för någon el. något'. Idiomet avser sålunda vållande av ett hinder. I vissa fall kan hindret betraktas som besvärande, men andra gånger som rent oöverstigligt. Med andra ord kan uttrycket betyda såväl 'försvåra för någon eller något' som 'stoppa någon/något'. Denna variation har emellertid ingen direkt koppling till vem eller vad det är som vållar hindret och vem eller vad som hindras. Men som framgår av definitionen är 
även faktorn 'avsiktligt' optionell, dvs. den manifesteras bara ibland. Denna variation är däremot nära förbunden med de typer av semantiska klasser som representerar det externa argument som fungerar som subjekt till uttrycket. Resonemanget kan förtydligas med hjälp av exempel (17) och (18):

(17) Saddam Hussein [...] har gång efter annan satt käppar i hjulet för FN och dess vapeninspektörer. (Press 96)

(18) Biogasvännerna befarar dock att lättköpt rysk naturgas sätter käppar $i$ hjulet för utveckling av andra dyrare förnybara energikällor - som vindkraft och solenergi. (Press 97)

I exempel (17), som gäller Saddam Hussein, torde det handla om ett avsiktligt och medvetet vållande av hinder. I (18) är det istället "lättköpt rysk naturgas" som vållar bekymmer, men naturgasen kan knappast anklagas för att avsiktligen och medvetet ha vållat detta problem. I (18) realiseras därmed inte faktorn 'avsiktligt'.

Ett annat exempel är se dagens ljus. Uttrycket, som uppvisar betydande semantisk variation i materialet, kan sägas betyda 'börja existera'. Den innehållsmässiga variationen hos idiomet har ett direkt samband med vad som representerar det externa argument som fungerar som subjekt till idiomet. Variationen framgår av följande fall:

(19) Det var alltså i en del av denna fastighet som Edvard Persson såg dagens ljus, närmare bestämt på Mjölnaregatan 5, tredje våningen. (Press 95)

(20) Superdatorerna såg dagens ljus 1989. De kunde redan utföra en miljard räkneoperationer i sekunden. (Press 97)

I det första exemplet ovan anges att en person, närmare bestämt sångaren och skådespelaren Edvard Persson, kommer till världen. I det fallet kan man säga att se dagens ljus betyder 'födas'. I exempel (20) är det dock en viss typ av maskin, nämligen superdatorer, som ser dagens ljus och betydelsen hos uttrycket är då snarare 'uppfinnas', 'börja att produceras'. Det är sålunda idiomets subjekt som i varje konkret fall avgör vad uttrycket i själva verket betyder. Resultatet kan jämföras med liknande iakttagelser som kunnat göras för t.ex. tyska och engelska (se vidare i bl.a. Fleischer 1997: 167; Moon 1998: 189). De olika betydelsenyanserna ryms dock inom den något vaga definitionen 'börja existera'. 
Som sista och avslutande exempel får idiomet slå mynt av något tjäna. Uttryckets definition kan sägas vara 'dra (ekonomisk) fördel av något'. Den semantiska variationen kan illustreras med följande två fall:

(15) Det verkar vara fullständig hysteri kring O J Simpson-rättegången i USA. Människor har alltid dragits till den snaskiga blandning av våld, sex och kändisskap Simpsonfallet uppvisar. Till det kommer det moderna kommersiella samhällets förmåga att slå mynt av intresset: Tshirts, dekaler och böcker går åt som smör en solig sommardag. (Press 95)

(16) Bill och Hillary Clinton har ansträngt sig till det yttersta för att ge sin dotter en normal uppväxt. Alla förfrågningar om intervjuer, bilder eller små anekdoter avvisas med ett bestämt nej. Andra politiker brukar inte dra sig för att slå mynt av söta telningar och familjegullande, men den opinionsmedvetne Clinton avstod från dessa lättköpta poänger. (Press 97)

Uttryckets definition, dvs. 'dra (ekonomisk) fördel av något', indikerar viss variation beträffande den typ av fördel som uttrycket gäller. I pressmaterialet handlar det främst om att dra ekonomisk fördel av något. Denna betydelse är också urskiljbar i exempel (15) ovan. Betydelsen 'dra fördel av något', som är aktuell i (16), är dock inte alls ovanlig. Idiomet används då om fördelar av mer allmänt slag. Uttryckets betydelse kan alltså i vissa fall sägas vara mer allmängiltig.

Tanken att idiomens betydelse ibland är mer generell är, som redan påtalats, i linje med hur förhållandet mellan lexemens grundbetydelser och underbetydelser beskrivs inom den lexikaliska databasen GLDB. Betydelsen 'dra ekonomisk fördel av något' kan sålunda betraktas som idiomets grundbetydelse och 'dra fördel av något' som en underbetydelse till denna. Med tanke på att uttryckets bokstavliga betydelse inbegriper just mynt, dvs. är hämtat ur ett ekonomiskt sammanhang, är inte denna utveckling helt otrolig ur ett diakront perspektiv. Man kan dock tänka sig en annan analys. Det kan vara 'dra fördel av något' som utgör idiomets grundbetydelse. Denna betydelse specificeras dock ytterligare i vissa kontexter.

Ännu en variant är att man betraktar den semantiska skillnaden mellan de två exemplen ovan som resultatet av ett byte av semantiska faktorer. I exempel (15) betyder slå mynt av något 'dra ekonomisk fördel av något'. I (16) kan idiomet istället sägas betyda 'dra politisk för- 
del av något'. Dessa preciseringar, dvs. att det rör sig om en fördel av ekonomisk, politiskt slag etc., måste man sålunda sluta sig till ur kontexten (jfr t.ex. Clausén 1996: 37 som konstaterar att den fulla innebörden hos ett idiom kommer fram först i en kontext).

\section{Avslutande diskussion}

I denna artikel diskuterar jag några olika typer av betydelsevariation som förekommer hos en grupp svenska idiom när dessa används i autentiska texter. Inledningsvis diskuteras variation som innebär att en specifik semantisk faktor, som utgör en del av idiomets idiomatiska betydelse, realiseras ibland. Därefter behandlas utbyte av semantiska faktorer och variation som gäller idiomens semantiska valens, dvs. vilka typer av semantiska klasser som representerar idiomets externa argument. Avslutningsvis tar jag upp mer komplexa fall där olika typer av variation är aktuella på samma gång. Genomgången visar att betydelsevariation hos idiom inte behöver omnämnas i svepande ordalag - såsom ofta sker i litteraturen. De former av betydelsevariation som är aktuella kan faktiskt preciseras ytterligare.

De olika variationstyperna som behandlas här kan tyckas vara av olika vikt. Enligt en sätt att analysera har exempelvis uttrycket slå mynt $a v$ något dels grundbetydelsen 'dra ekonomisk fördel av något', dels underbetydelsen 'dra allmän fördel av något'. Järborg (1996: 12) konstaterar att förekomsten av en underbetydelse är ett typiskt förstadium till en eventuell splittring av ett lexem, dvs. att lexemet blir polysemt. Detsamma torde kunna gälla för idiomatiska uttryck.

Den variation som gäller hur uttryckens externa argument representeras kan i viss mån betraktas som marginell. Det kan tyckas mindre relevant om idiomet lysa med sin frånvaro kombineras med ett argument som representeras av en person eller av en abstrakt företeelse. Andra gånger, såsom i fråga om se dagens ljus, är det dock den semantiska klassen hos det ord som representerar det externa argumentet som avgör om uttrycket betyder 'födas' eller 'börja att produceras'.

Avslutningsvis kan jag konstatera att föreliggande arbete har flera utvecklingsmöjligheter. Järborg (1989: 7-8, 1996: 3, 12) konstaterar att lexemets kärnbetydelse modifieras till olika användningsbetydelser med hjälp av en uppsättning generella lexikalisk-semantiska regler. Några sådana regler beskrivs i bl.a. Malmgren (1988) och Järborg (1996: 19-24, 
2003: 44-45) (jfr t.ex. Jonsson 2003). Det vore exempelvis intressant att på ett mer djupgående sätt jämföra de semantiska transfereringsregler som gäller för lexem med de typer av idiomvariation som diskuteras här och undersöka i vilken mån det rör sig om liknande mekanismer.

\section{Litteratur}

Aitchison, Jean 2003 [1987]: Words in the mind. An introduction to the Mental Lexicon. 3 ed. Oxford: Clarendon Press.

Barkema, Henk 1996: The effect of inherent and contextual factors on the grammatical flexibility of idioms. In Percy, Carol E./Meyer, Charles F./Lancashire, Ian (eds.), Synchronic corpus linguistics. Papers from the sixteenth International Conference on English Language Research and Computerized Corpora (ICAME 16), 69-83. (Language and computers: Studies in practical linguistics 16.) Amsterdam/Atlanta: Rodopi.

Barkema, Henk 1997: The grammatical freedom of lexicalised noun phrases. In Ljung, Magnus (ed.), Corpus-based Studies in English. Papers from the seventeenth International Conference on English Language Research and Computerized Corpora (ICAME 17), 49-68. (Language and computers: Studies in practical linguistics 20.) Amsterdam/Atlanta: Rodopi.

Burger, Harald 1998: Phraseologie: eine Einführung am Beispiel des Deutschen. (Grundlagen der Germanistik 36.) Berlin: Erich Schmidt.

Burger, Harald 1999: Phraseologie in der Presse. In Fernandez Bravo, Nicole/Behr, Irmtraud/Rozier, Claire (Hrsg.), Phraseme und typisierte Rede, 77-89. (Eurogermanistik. Europäische Studien zur deutschen Sprache 14.) Tübingen: Stauffenburg.

Clausén, Ulla 1996: Idiom i bruk. In Språket lever! Festskrift till Margareta Westman den 27 mars 1996, 36-42. (Skrifter utgivna av Svenska språknämnden 80.) Stockholm: Norstedts.

Corpas Pastor, Gloria 1996: Manual de la fraseología española. Madrid: Gredos.

Dobrovol'skij, Dmitrij 1992: Phraseological universals: theoretical and applied aspects. In Kefer, Michel/van der Auwera, Johan (eds.), Meaning and Grammar. CrossLinguistic Perspectives, 279-301. (Empirical Approaches to Language Typology 10.) Berlin/New York: Mouton de Gruyter.

Fleischer, Wolfgang 1997: Phraseologie der deutschen Gegenwartssprache. 2. durchgesehene und ergänzte Auflage. Tübingen: Niemeyer.

Jonsson, Hans 2003: Metaforen som semantisk händelse. (Skrifter utgivna av Vetenskapssocieteten i Lund 95.) Lund.

Järborg, Jerker 1989: Betydelseanalys och betydelsebeskrivning i Lexikalisk databas. Institutionen för svenska språket, Göteborgs universitet (stencil). Göteborg. 
Järborg, Jerker 1996: Formaliserad lexikologi. Rapport från ett långtidsprojekt. (Research Reports from the Department of Swedish, Göteborg University). Göteborg.

Järborg, Jerker 2003: Formaliserade semantiska samband mellan enheter i GLDB. (Research Reports from the Department of Swedish, Göteborg University). Göteborg.

Koller, Werner 1977: Redensarten. Linguistische Aspekte, Vorkommensanalysen, Sprachspiel. Tübingen: Niemeyer.

Lindfors Viklund, Maja 1991: Svenska idiom. Ur ett internationellt perspektiv. (Rapporter från Institutionen för nordiska språk/svenska språket vid Göteborgs uni_versitet (Nordrapp) 7). Göteborg.

Malmgren, Sven-Göran 1988: On Regular Polysemy in Swedish. In Studies in Computer-Aided Lexicology 179-200. (Data Linguistica 18). Stockholm: Almqvist \& Wiksell International.

Moon, Rosamund 1998: Fixed Expressions and Idioms in English. A Corpus-Based Approach. New York: Clarendon Press.

Målande uttryck. En liten bok med svenska idiom 1989: Utarbetad vid Språkdata, Göteborgs universitet. Stockholm.

Nationalencyklopedin, 1994: Band 14. Höganäs: Bra böcker.

Nationalencyklopedins ordbok, 1995-96: Del 1-3. Höganäs: Bra böcker.

Norén, Kerstin 1996: Svenska partikelverbs semantik. (Acta Universitatis Gothoburgensis: Nordistica Gothoburgensia 17). Göteborg.

Ordbok över svenska språket, utgiven av Svenska Akademien (SAOB) 1898-. Lund: Gleerups.

Skog-Södersved, Mariann 1992: Zum Vorkommen von Phraseolexemen in Leitartikeln deutscher und schwedischer Tageszeitungen. In Korhonen, Jarmo (Hrsg.), Untersuchungen zur Phraseologie des Deutschen und anderer Sprachen: einzelsprachspezifisch - kontrastiv - vergleichend. Internationale Tagung in Turku 6.-7.9.1991, 175-188. (Werkstattreihe Deutsch als Fremdsprache 40). Frankfurt am Main: Peter Lang.

Sköldberg, Emma 2004: Korten på bordet. Innehålls- och uttrycksmässig variation hos svenska idiom. (Meijerbergs arkiv för svensk ordforskning 31). Göteborg.

Svanlund, Jan 2001: Metaforen som konvention. Graden av bildlighet i svenskans viktoch tyngdmetaforer. (Acta Universitatis Stockholmiensis, New Series 23). Stockholm.

Svensk ordbok 1986: Utarbetad vid Språkdata, Göteborgs universitet. Solna: Norstedts.

Toporowska Gronostaj, Maria 1996: Integrerad valensbeskrivning. Mot ett formaliserat verbvalenslexikon. Göteborgs universitet: Institutionen för svenska språket. Göteborg. 
Använda web-adresser:

$<$ http://spraakbanken.gu.se $>$ 